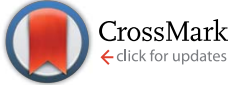

Cite this: RSC Adv., 2017, 7, 13003

Accepted 17th February 2017

DOI: $10.1039 / \mathrm{c} 6 \mathrm{ra2} 8628 \mathrm{c}$

rsc.li/rsc-advances

\section{The reactive wetting kinetics of interfacial tension: a reaction-limited model $\dagger$}

\author{
Yongbin Ren, Rongsheng Zhou, Dingyi Zhu* and Teng Zhang* \\ A new dynamics model describing the time-dependent change of solid-liquid interfacial tension is first \\ established to explain the driving force and physical essence of the spreading process of reaction-limited \\ wetting. The model has been successfully verified through the wetting experiments of $\mathrm{Al}-\mathrm{Si} / \mathrm{SiC}$ systems \\ (Si content $=0,7,12 \mathrm{wt} \%$, respectively) at different temperatures, in which the logarithmic plots of \\ driving force versus time present a linear relationship in the reaction-limited spreading stage. \\ Furthermore, the mechanisms of reactive spreading are discussed in detail.
}

\section{Introduction}

During the past few decades, the mechanisms of reactive wetting and spreading with solidification in various systems have been under extensive investigations. ${ }^{\mathbf{1 - 1 8}}$ Most of the reported studies focus on the effect of interfacial reactions on the spreading kinetics, and there are some dynamics models of spreading, e.g., the molecular dynamics model of Blake and Haynes, ${ }^{19}$ the semi-empirical formula of de Gennes, ${ }^{20}$ the diffusion-limited model of Mortensen et al., ${ }^{9}$ and the characteristic equation of the reaction-limited spreading model by Dezellus et al. ${ }^{21}$ From Young's equation, ${ }^{22}$ one can see that solid-liquid interfacial tension $\left(\gamma_{\mathrm{sl}}\right)$ is indeed an essential factor affecting the spreading process.

$$
\gamma_{\mathrm{sv}}=\gamma_{\mathrm{sl}}+\gamma_{\mathrm{lv}} \cos \theta_{\mathrm{e}}
$$

Where $\gamma_{\mathrm{sv}}$ is solid-vapor surface tension, $\gamma_{\mathrm{lv}}$ is liquid-vapor surface tension, $\theta_{\mathrm{e}}$ is the equilibrium contact angle. In our opinion, the commonalities of all the reactive wetting systems are the variation of interfacial character, which is related to $\gamma_{\mathrm{sl}}$ directly. However, most dynamics models mentioned above are built on the basis of a macroscopic perspective, which show a similar relationship between dynamic contact angle $(\theta)$ or spreading radius $(R)$ versus time $(t)$. A detailed explanation of wetting mechanism based on the $\gamma_{\mathrm{sl}}$ is rarely given i.e. there is few dynamics models about the decrease rate of $\gamma_{\mathrm{sl}}$ which is important to study the reactive wetting dynamics.

Some phenomena in reactive wetting system can be essentially explained by $\gamma_{\mathrm{sl}}$ theory. For example, the interfacial reaction can be realized in $\mathrm{Cu}-10$ at $\% \mathrm{Si} / \mathrm{C}$ system through the dissolution

College of Materials Science and Engineering, Fuzhou University, Fuzhou, Fujian 350108, China.E-mail: teng_zhang@fzu.edu.cn; zdy7081@163.com; Fax: +86591 22866537; Tel: +8659122866540

$\dagger$ Electronic supplementary information (ESI) available. See DOI: $10.1039 / \mathrm{c} 6 \mathrm{ra} 28628 \mathrm{c}$ of carbon atoms in liquid alloy with $\theta$ unchanging. ${ }^{21}$ There is no chemical reaction in the system, so the $\gamma_{\mathrm{sl}}$ keeps constant. This phenomenon means that the change of $\theta$ should be attributed to the $\gamma_{\mathrm{sl}}$. The same inference can also be drawn from the other common reactive wetting systems..$^{2324}$ Once the $\gamma_{\mathrm{sl}}$ becomes stable, the $\theta$ will not change. In conclusion, $\gamma_{\mathrm{sl}}$ is the most fundamental starting point for understanding the complex field of wetting, which definitely deserves a further investigation.

The primary purpose of our work reported in this paper is to build a new dynamics model from the view point of $\gamma_{\mathrm{sl}}$ to explain the driving force and wetting mechanism. The wetting experiments of $\mathrm{Al} / \mathrm{SiC}, \mathrm{Al}-7 \mathrm{wt} \% \mathrm{Si} / \mathrm{SiC}$ and $\mathrm{Al}-12 \mathrm{wt} \% \mathrm{Si} / \mathrm{SiC}$ systems at different temperatures have been investigated through a improved sessile drop method to examine the rationality of the model. The measurements on reactive surface can also take place if more moderate conditions are investigated like water on a reactive de-wetting on freshly cleaned silicon wafer surface. ${ }^{25}$

\section{Experimental procedure}

For all contact angle (CA) measurements, $98.5 \mathrm{wt} \%$ pure silicon carbide (SiC) solid plates, with a density of $3.1 \mathrm{~g} \mathrm{~cm}^{-3}$ and dimensions of $20 \mathrm{~mm}$ in diameter and $5 \mathrm{~mm}$ in thickness, are used as substrate. The Al specimens with a purity of $99.999 \mathrm{wt} \%$ are in the form of small cubes with dimensions of $3 \times 3 \times 3$ $\mathrm{mm}^{3}$. The Al-Si alloys are prepared by arc-melting of high-purity $\mathrm{Al}$ (99.999 wt\%) and Si (99.999 wt\%) plates in argon (99.999 wt\% purity) atmosphere, where $\mathrm{Ti}$ ( $99.8 \mathrm{wt} \%$ purity) metals are put inside to getter oxygen impurities. The raw materials are melted and solidified in a water-cooled copper crucible four times under constant electromagnetic stirring. And then the obtained $\mathrm{Al}-\mathrm{Si}$ alloys are cut into cubes with dimensions of $3 \times 3 \times 3$ $\mathrm{mm}^{3}$. The surfaces of SiC substrates are mechanically polished by different micrometer-size diamond pastes and the average roughness is $20 \mathrm{~nm}$. Before the wetting experiments, both the substrates and specimens are ultrasonically cleaned in alcohol. 
Table 1 The relevant datas of $\mathrm{Al} / \mathrm{SiC}$ system at different temperatures ${ }^{a}$

\begin{tabular}{|c|c|c|c|c|c|c|}
\hline Temperature/K & $\theta_{\text {ini }}(\mathrm{Al}) /^{\circ}$ & $\theta_{\mathrm{fin}}(\mathrm{Al}) /^{\circ}$ & $\theta_{\text {ini }} / \theta_{\text {fin }}$ & $k$ & $c$ & Fitting range \\
\hline 973 & 125 & 95 & 1.31 & - & 1 & - \\
\hline 1073 & 117 & 91 & 1.28 & - & 1 & - \\
\hline 1173 & 109 & 57 & 1.90 & $3.73 \times 10^{-4}$ & 1 & $157-3307 \mathrm{~s}$ \\
\hline 1273 & 105 & 57 & 1.86 & $4.12 \times 10^{-3}$ & 1 & $36-255 \mathrm{~s}$ \\
\hline
\end{tabular}

Table 2 The relevant datas of $\mathrm{Al}-7 \mathrm{Si} / \mathrm{SiC}$ system at different temperatures

\begin{tabular}{|c|c|c|c|c|c|c|}
\hline Temperature/K & $\begin{array}{l}\theta_{\text {ini }}(\mathrm{Al}-7 \\
\left.\mathrm{wt}^{2} \% \mathrm{Si}\right){ }^{\circ}\end{array}$ & $\begin{array}{l}\theta_{\text {fin }}(\mathrm{Al}-7 \\
\mathrm{wt} \% \mathrm{Si}){ }^{\circ}\end{array}$ & $\theta_{\text {ini }} / \theta_{\text {fin }}$ & $k$ & $c$ & Fitting \\
\hline 973 & 121 & 90 & 1.34 & - & 0.93 & - \\
\hline 1073 & 109 & 73 & 1.50 & $5.5252 \times 10^{-4}$ & 0.93 & $0-1131 \mathrm{~s}$ \\
\hline 1123 & 105 & 74 & 1.42 & $1.39 \times 10^{-3}$ & 0.93 & $0-566 \mathrm{~s}$ \\
\hline 1173 & 101 & 72 & 1.40 & $5.53 \times 10^{-3}$ & 0.93 & $0-124 \mathrm{~s}$ \\
\hline
\end{tabular}

The wetting experiments are investigated through a dispensed sessile drop method under high vacuum $\left(10^{-4} \mathrm{~Pa}\right)$, which is proposed by Shen et al. ${ }^{\mathbf{2 6 - 2 8}}$ One significant characteristic of this method is that the droplets and substrates are separated before the wetting experiments to avoid pre-reaction upon heating. Besides, the initial oxide layers covering the molten $\mathrm{Al}$ droplet can be mechanically stripped to obtain a more exact measurement result of the $\theta$ and the spreading dynamics. The contact between different parts of the wetting system begins when the predetermined testing temperature is reached. In a typical wetting experiment procedure, the molten $\mathrm{Al}$ is slowly extruded through a narrow orifice at the bottom of an alumina tube (99.6 wt\%) and then rested horizontally onto the SiC surface. During the wetting procedure, the $\theta$ is directly measured from drop profiles using an axisymmetric drop shape analysis (ADSA) program. ${ }^{29}$ The detailed description of the performed experiments can be found in the ESI. $\dagger$ The wetting experiments are carried out at 973-1273 K (Tables 1 and 2).

\section{Modelling and deducing}

Here, we try to explain problems in reactive wetting by using changes for $\gamma_{s l}$. First of all, Fig. 1(a) is a schematic diagram of the Young's equation, in which the diameter of the drop is relatively less than the size of the substrate and the $\theta_{1}$ is the initial contact angle. While Fig. 1(b) is a schematic diagram of the equilibrium state in a finite interface designed for this study, the $\theta_{2}\left(\theta_{2} \rightarrow\right.$ $\left.\theta_{\text {max }}\right)$ of which is defined as the theoretical maximum contact angle when gravitational pull is neglected and loss is prevented at the initial state. According to tensions balance on the horizontal and vertical direction, eqn (2) and (3) can be obtained:

$$
\begin{gathered}
\gamma_{\mathrm{sl}}=-\gamma_{\mathrm{lv}} \cos \theta_{2}, 90^{\circ} \leq \theta_{2} \leq 180^{\circ} \\
\gamma_{\mathrm{sv}}=\gamma_{\mathrm{lv}} \sin \theta_{2}, 90^{\circ}<\theta_{2} \leq 180^{\circ}
\end{gathered}
$$

Chemical reactions existing at the interface of reactive wetting systems would change the physicochemical properties of solid-liquid interface. Now we assume that the interfacial chemical reaction is a combination reaction:

$$
\mathrm{A}+\mathrm{B} \rightarrow \mathrm{AB}
$$

It has been found that the value of $\gamma_{\mathrm{sl}}$ would reduce during the whole wetting process, which leads to the spreading of the liquid at the interface. ${ }^{30}$ Basing on this, one can assume that the driving force of wetting process is related to $\Delta \gamma_{\mathrm{sl}}(t)$ through the following relation:

$$
\Delta \gamma_{\mathrm{sl}}(t)=\gamma_{\mathrm{sl}}(t)-\left(\gamma_{\mathrm{sl}}\right)_{\mathrm{e}}
$$

where $\gamma_{\mathrm{sl}}(t)$ and $\left(\gamma_{\mathrm{sl}}\right)_{\mathrm{e}}$ are the dynamic and equilibrium solidliquid interfacial tensions, respectively. The decrease rate of interfacial tension, $\mathrm{d} \gamma_{\mathrm{sl}} / \mathrm{d} t$, is an important parameter to describe the wetting mechanism. Usually, the value of $\mathrm{d} \gamma_{\mathrm{sl}} / \mathrm{d} t$ is in proportion to $\Delta \gamma_{\mathrm{sl}}(t)$ and the interfacial reaction rate $v$. We can roughly describe the rate of interfacial tension change as follow:

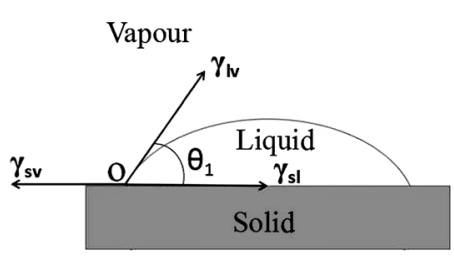

(a)

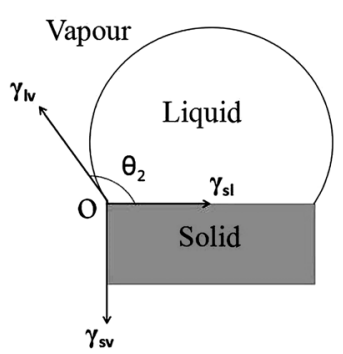

(b)
Fig. 1 The wetting schematic diagrams of (a) infinite and (b) finite solid-liquid interface. 


$$
\frac{\mathrm{d} \gamma_{\mathrm{sl}}}{\mathrm{d} t}=\Delta \gamma_{\mathrm{sl}}(t) v
$$

Combining eqn (5) and (6), the following expression of $\mathrm{d} \gamma_{\mathrm{sl}} /$ $\mathrm{d} t$ is derived:

$$
\frac{\mathrm{d} \gamma_{\mathrm{sl}}}{\mathrm{d} t}=\left[\gamma_{\mathrm{sl}}(t)-\left(\gamma_{\mathrm{sl}}\right)_{\mathrm{e}}\right] v
$$

where $v$ is related to temperature and concentration of active atoms. Assume that the reactive wetting system is controlled by interfacial chemical reaction, the value of $v$ could be described as follow:

$$
-v=k C_{\mathrm{A}}^{n_{1}} C_{\mathrm{B}}^{n_{2}}
$$

where $C_{\mathrm{A}}, C_{\mathrm{B}}$ is the concentration of active atoms for reactant $\mathrm{A}$ and $\mathrm{B}$, respectively. $n_{1}, n_{2}$ is the reaction order for reactant $\mathrm{A}$ and $\mathrm{B}$, respectively. For wetting systems in this work, the interfacial reaction is the first-order reaction, and then:

$$
-v=k C
$$

where $C$ is the consumed concentration of active atoms in the liquid phase, and $k$ is reaction rate constant following the Arrhenius equation:

$$
k=k_{0} \exp \left(-\frac{E_{\mathrm{a}}}{R T}\right)
$$

where $k_{0}$ is the pre-exponential factor, $E_{\mathrm{a}}$ is the activation energy, $R$ is the molar gas constant, and $T$ is the thermodynamic temperature.

Integrating eqn (7), the following equation can be produced:

$$
\int \frac{1}{\gamma_{\mathrm{sl}}(t)-\left(\gamma_{\mathrm{sl}}\right)_{\mathrm{e}}} \mathrm{d} \gamma_{\mathrm{sl}}=\int v \mathrm{~d} t
$$

It can be simplified as:

$$
\ln \left[\gamma_{\mathrm{sl}}(t)-\left(\gamma_{\mathrm{sl}}\right)_{\mathrm{e}}\right]=v t+b
$$

where $b$ is integration constant. When $t=0$, and then:

$$
b=\ln \left[\left(\gamma_{\mathrm{sl}}\right)_{\mathrm{i}}-\left(\gamma_{\mathrm{sl}}\right)_{\mathrm{e}}\right]=\ln \left(\Delta \gamma_{\mathrm{sl}}\right)_{\max }
$$

Eqn (12) leads to the following expression:

$$
\begin{gathered}
\gamma_{\mathrm{sl}}(t)=\left(\gamma_{\mathrm{sl}}\right)_{\mathrm{e}}+\left(\Delta \gamma_{\mathrm{sl}}\right)_{\max } \exp (-k C t) \\
\frac{\mathrm{d} \gamma_{\mathrm{sl}}(t)}{\mathrm{d} t}=-\left(\Delta \gamma_{\mathrm{sl}}\right)_{\max } k C \exp (-k C t)
\end{gathered}
$$

The features of the dynamics model derived from an interfacial tension perspective could be summarized as followed: (i) It relates $\gamma_{\mathrm{sl}}$ directly to the spreading time by an exponential relationship.

(ii) The greater the driving force is, the faster the interfacial tension decreases.

(iii) Both the interfacial reaction velocity and the decrease rate of interfacial tension present a positive correlation with the temperature and the concentration of interfacial reactive atoms, in accordance with the basic rules of solid-liquid interfacial reactions.

\section{Experiment verification}

\subsection{The relationship between the contact angle and time}

In order to verify the rationality of the dynamics model proposed above, we investigated the wetting procedures of Al$\mathrm{Si} / \mathrm{SiC}$ systems (Si content $=0,7,12 \mathrm{wt} \%$, respectively) from the point of view of $\gamma_{\mathrm{sl}}$.

For $\mathrm{Al} / \mathrm{SiC}, \mathrm{Al}-7 \mathrm{wt} \% \mathrm{Si} / \mathrm{SiC}$ and $\mathrm{Al}-12 \mathrm{wt} \% \mathrm{Si} / \mathrm{SiC}$ systems, Cong et $a .^{28}$ have already published their findings of the relations between $\theta$ and $t$ at temperatures ranging from 973 to $1273 \mathrm{~K}$. A transition from non-wetting (i.e., $\theta_{\mathrm{e}} \geq 90^{\circ}$ ) to wetting (i.e., $\theta_{\mathrm{e}}<90^{\circ}$ ) observed at a temperature in the $\mathrm{Al} / \mathrm{SiC}$ system suggests that the interfacial reaction between $\mathrm{Al}$ and $\mathrm{SiC}$ may be not obvious at $T \leq$ $1073 \mathrm{~K}$, while it is significant at $T \geq 1123 \mathrm{~K}$. The contact angle in the $\mathrm{Al}-7 \mathrm{wt} \% \mathrm{Si} / \mathrm{SiC}$ system experienced a hysteresis stage after rapid spreading at 1073-1173 $\mathrm{K}$, which is not observed in the Al-12 wt $\% \mathrm{Si} / \mathrm{SiC}$ system. This phenomenon may be related to the concentration of $\mathrm{Si}$ atom. The reasons for the changes in contact angle are complicated which can not be only described as a total exponential decay process (e.g., Gompertz's law ${ }^{31}$ ). Detailed descriptions can be seen from their report. In all cases mentioned above, an increase of temperature would produce an acceleration of spreading velocity as illustrated by the decrease of spreading time.

\subsection{The relationship between the interfacial tension and time}

Based on the concept of infinite and finite solid-liquid interface, as shown in Fig. 1. The reactive wetting equations for finite wetting systems have been defined by our previous work and an efficient computational method for the reactive solid-liquid interfacial tension is listed as follow: ${ }^{32}$

$$
\begin{gathered}
\gamma_{\mathrm{sv}}=\gamma_{\mathrm{sl}}+\gamma_{\mathrm{lv}}\left[\cos \theta_{1}-f\left(\theta_{1}\right)\right], 0^{\circ} \leq \theta_{1} \leq 180^{\circ} \\
\gamma_{\mathrm{sv}}=\gamma_{\mathrm{lv}} \sin \theta_{2}, 90^{\circ} \leq \theta_{2} \leq 180^{\circ} \\
\gamma_{\mathrm{sl}}=\gamma_{\mathrm{lv}} \frac{2\left(\cos ^{2} \theta_{2}-3\right)+\sqrt[3]{16}\left(2+\cos \theta_{2}\right)^{\frac{4}{3}}\left(1-\cos \theta_{2}\right)^{\frac{2}{3}}}{\left(1+\cos \theta_{2}\right)^{2}} \\
90^{\circ} \leq \theta_{2} \leq 180^{\circ}
\end{gathered}
$$

with

$$
f\left(\theta_{1}\right)=\frac{\left(\cos ^{3} \theta_{1}+4 \cos ^{2} \theta_{1}+\cos \theta_{1}-6\right)+\sqrt[3]{16}\left(2+\cos \theta_{1}\right)^{\frac{4}{3}}\left(1-\cos \theta_{1}\right)^{\frac{2}{3}}}{\left(1+\cos \theta_{1}\right)^{2}}
$$


Detailed derivation steps of above equations can be seen in the ESI. $\uparrow$ Compared with the equilibrium Young's equation, eqn (16) is relatively more universal for reactive wetting on infinite solid-liquid interface with an angle correct factor $f(\theta)$, which is built on the basis of the work performed by unbalanced forces at non-equilibrium. For given solid and liquid matters, the numerical values of $\gamma_{\mathrm{sv}}$ and $\gamma_{\mathrm{lv}}$ have uniqueness. Eqn (17) and (18) could be applied to describe the initial state of reactive wetting on finite solid-liquid interface only. As the initial interfacial tension $\left(\gamma_{\mathrm{sl}}\right)_{\mathrm{i}}$ of the two systems is identical, the mathematical relation between initial $\theta_{1}$ and $\theta_{2}$ could be derived:

$$
\begin{aligned}
& \cos \theta_{1}-f\left(\theta_{1}\right)= \\
& \sin \theta_{2}-\frac{2\left(\cos ^{2} \theta_{2}-3\right)+\sqrt[3]{16}\left(2+\cos \theta_{2}\right)^{\frac{4}{3}}\left(1-\cos \theta_{2}\right)^{\frac{2}{3}}}{\left(1+\cos \theta_{2}\right)^{2}}
\end{aligned}
$$

According to the analysis above, once the initial contacting angle $\theta_{1}$ of infinite solid-liquid interface is measured, the $\theta_{2}$ will be figured out by eqn (20), and then the corresponding $\gamma_{\mathrm{sv}}$ and $\left(\gamma_{\mathrm{sl}}\right)_{\mathrm{i}}$ will be determined through eqn (17) and (18), respectively. Thus the $\theta(t)$ curves can be converted into $\gamma_{\mathrm{sl}}(t)$ curves through eqn (16).

Fig. 2(a)-(c) demonstrate the variations of $\gamma_{\mathrm{sl}}$ with time for $\mathrm{Al} /$ $\mathrm{SiC}, \mathrm{Al}-7 \mathrm{wt} \% \mathrm{Si} / \mathrm{SiC}$ and $\mathrm{Al}-12 \mathrm{wt} \% \mathrm{Si} / \mathrm{SiC}$ systems at different temperatures, respectively. We can see that the trends of the $\gamma_{\mathrm{sl}}(t)$ curves are consistent with the corresponding $\theta(t)$ curves for three wetting systems. As the spreading is fast at higher temperature, the drop can reach a final equilibrium state in a relatively shorter time, such as $\mathrm{Al} / \mathrm{SiC}$ system at $1273 \mathrm{~K}$, while some curves at lower temperature still have not reached their equilibrium states by the end of the testing time, suggesting that the interfacial reactions between the molten droplets and the SiC substrates at lower temperature should not be very significant. As shown in Fig. 2(d), three kinetic stages can be defined on the $\gamma_{\mathrm{sl}}(t)$ curve of $\mathrm{Al} / \mathrm{SiC}$ system at $1173 \mathrm{~K}$ between $t_{0} \approx 0$ and $t_{3}$. In the first stage $\left(t_{0}<t\right.$ $<t_{1}$ ), the $\gamma_{\mathrm{sl}}$ decreases rapidly with time, which might be explained by the reaction between $\mathrm{Al}$ and $\mathrm{SiO}_{2}$ on the oxidized $\mathrm{SiC}$ surface. The second stage $\left(t_{1}<t<t_{2}\right)$ is called as reaction-limited spreading, in which the $\gamma_{s l}$ decreases slowly with time. This suggests an interfacial reaction happening between $\mathrm{Al}$ and $\mathrm{SiC}$. In the third stage $\left(t_{2}<t<t_{3}\right)$, the $\gamma_{\mathrm{sl}}$ nearly keeps a constant value of $300 \mathrm{mN} \mathrm{m}^{-1}$. This phenomenon reveals that the reaction between $\mathrm{Al}$ and $\mathrm{SiC}$ reaches an equilibrium state at $t_{2}$, i.e., the $\mathrm{Al} /$ SiC system stays at a diffusion-limited spreading stage from $t_{2}$ to $t_{3} .{ }^{33}$ For $\mathrm{Al}-7 \mathrm{wt} \% \mathrm{Si} / \mathrm{SiC}$ system, there is a hysteresis stage after initial rapid spreading at 1073-1173 K, because the driving force we proposed is close to 0 and the retarding force resulted from the rough interface of the reaction product $\mathrm{Al}_{4} \mathrm{C}_{3}$ is large enough to inhibit the movement of the triple line. However, increasing temperature can favor deoxidization by a self-cleaning reaction in a high vacuum and also accelerates the reaction between $\mathrm{Al}$ and SiC. As a consequence, the spreading can continue to happen in Al-7 wt\% Si/SiC system at $1273 \mathrm{~K}$. Such stranded behavior is not observed in the $\mathrm{Al}-12 \mathrm{wt} \% \mathrm{Si} / \mathrm{SiC}$ system because the reaction is fully inhibited (i.e., the interface roughness of $\mathrm{Al}-12 \mathrm{wt} \% \mathrm{Si} / \mathrm{SiC}$ system is quite smaller than that of $\mathrm{Al}-7 \mathrm{wt} \% \mathrm{Si} / \mathrm{SiC}$ system)
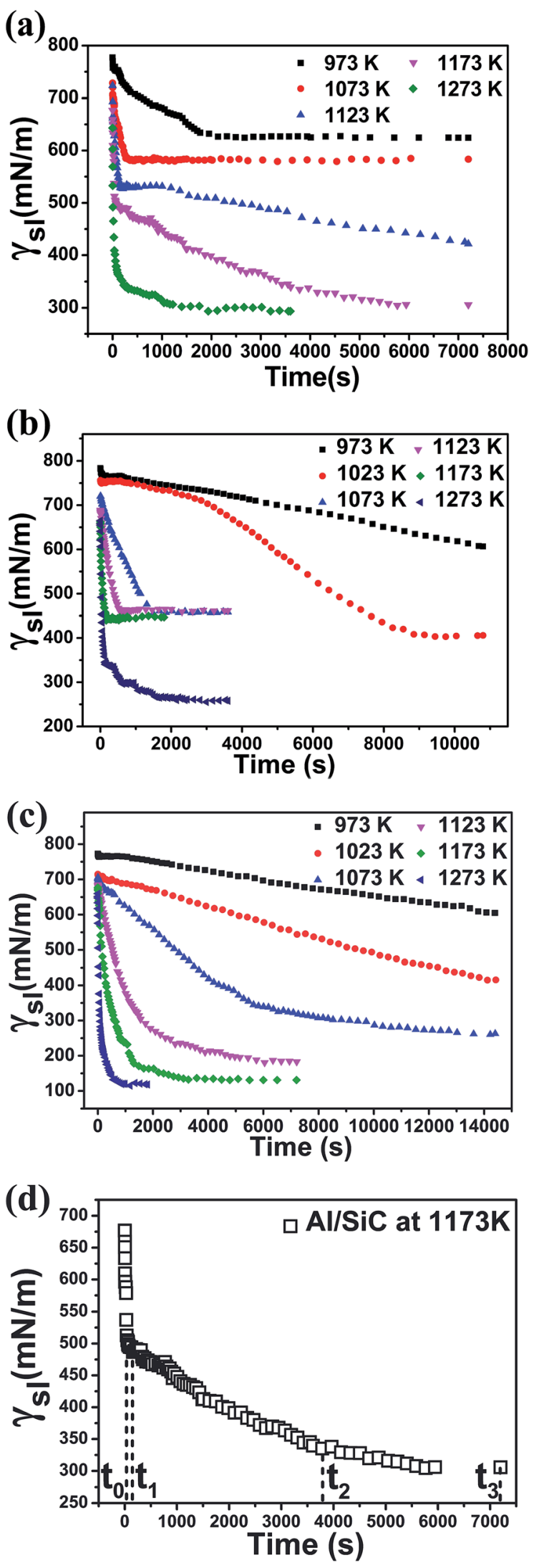

Fig. 2 Variations in the dynamic interfacial tension with time for (a) Al/ $\mathrm{SiC}$ system, (b) Al-7 wt\% Si/SiC system, (c) Al-12 wt\% Si/SiC system at different temperatures and (d) $\mathrm{Al} / \mathrm{SiC}$ system at $1173 \mathrm{~K}$. 

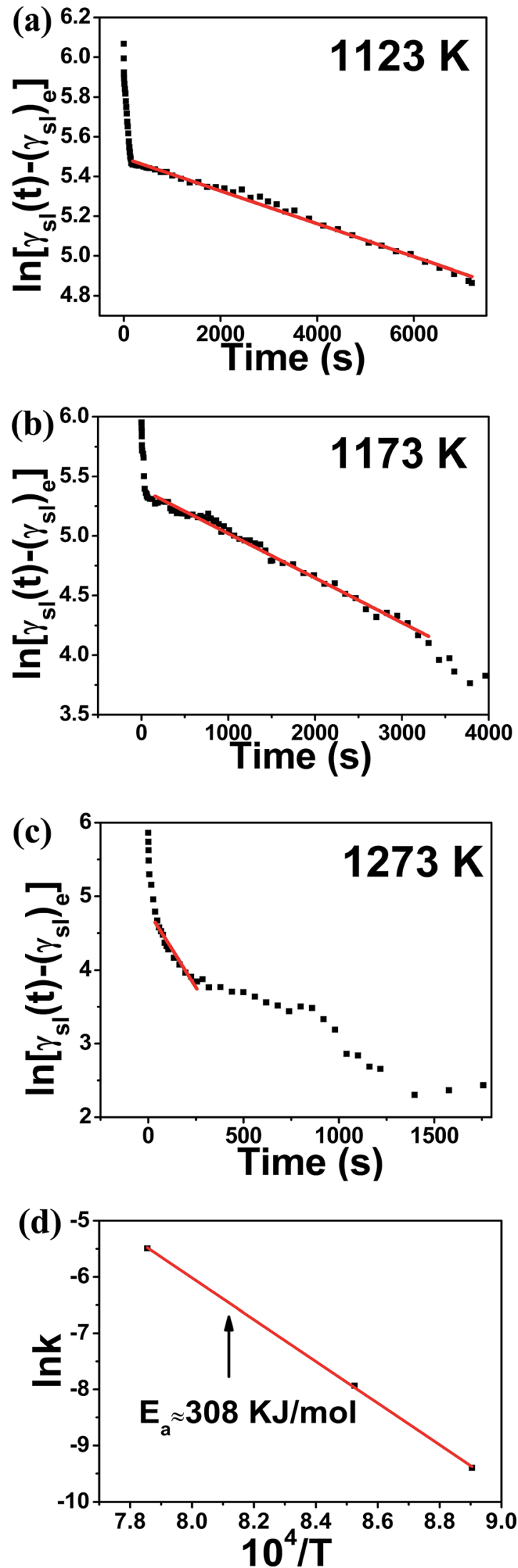

Fig. $3 \ln \left[\gamma_{\mathrm{sl}}(t)-\left(\gamma_{\mathrm{sl}}\right)_{\mathrm{e}}\right]$ versus time for Al/SiC system at temperatures (a) $1123 \mathrm{~K}$, (b) $1173 \mathrm{~K}$, and (c) $1273 \mathrm{~K}$, respectively; (d) Arrhenius plot of In K against $104 / T$ for calculation of the activation energy of the spreading $\left(E_{\mathrm{a}}\right)$ in the second stage. and the driving force is large enough to overcome the impedance. The equilibrium Si content required to prevent the formation of $\mathrm{Al}_{4} \mathrm{C}_{3}$ as a function of temperature has been investigated in many works $^{34-38}$ through theoretical calculations and experimental methods.

\subsection{The verification of the dynamics model of reactive wetting}

Fig. 3(a-c) show the logarithmic plots of $\gamma_{\mathrm{sl}}(t)-\left(\gamma_{\mathrm{sl}}\right)_{\mathrm{e}}$ as a function of time for $\mathrm{Al} / \mathrm{SiC}$ system at different temperatures. In the reaction-limited spreading stage, as fitted by the red line, the linear correlation coefficients $R$ is very close to unity $\left(R^{2}>0.99\right)$ in all cases. It is noted that in order to draw the straight line, the value chosen for $\left(\gamma_{\mathrm{sl}}\right)_{\mathrm{e}}$ must be a little smaller than the experimental value in the reaction-limited spreading stage to avoid the mutation of the curve. Based on the eqn (9) and the Arrhenius law, where $k C$ ( $C=1$ for pure $\mathrm{Al}$ ) is the slope of the fitting curves (see eqn (12)), the activation energy $E_{\mathrm{a}}$ in this linear spreading stage is calculated to be $308 \mathrm{~kJ} \mathrm{~mol}^{-1}$, as shown in Fig. 3(d). This result is close to the activation energy of $330 \mathrm{~kJ} \mathrm{~mol}^{-1}$ for $\mathrm{Al} / \mathrm{SiC}$ system evaluated by Choh and Oki, ${ }^{39}$ who measured the wetting rates in the range of 1173-1373 K using a dip coverage method. The slope of the fitted straight line $(k)$ in Fig. $3(\mathrm{a}-\mathrm{c})$ are $-8.29 \times 10^{-5},-3.73$ $\times 10^{-4}$ and $-4.12 \times 10^{-3}$, respectively, which indicated that an increase in temperature would produce a strong acceleration of the interfacial reaction rate. Similar results can be drawn for Al-7 wt\% $\mathrm{Si} / \mathrm{SiC}$ system in the reaction-limited spreading stage, as shown in Fig. 4, with the linear correlation coefficients $R$ close to unity $\left(R^{2}>0.99\right)$ too. The slope of the fitted straight line $(k C)$ are $-5.5252 \times 10^{-4},-1.39 \times 10^{-3}$ and $-5.53 \times 10^{-3}$, respectively.

Furthermore, the phenomenon of $\mathrm{Al}-12 \mathrm{wt} \% \mathrm{Si} / \mathrm{SiC}$ system is unique, as indicated in Fig. 5, the slope of the fitted line in Al-12 $\mathrm{wt} \% \mathrm{Si} / \mathrm{SiC}$ system $\left(-1.73 \times 10^{-3}\right)$ at $1173 \mathrm{~K}$ is smaller than that of $\mathrm{Al}-7 \mathrm{wt} \% \mathrm{Si} / \mathrm{SiC}$ system $\left(-5.53 \times 10^{-3}\right)$. In general, two reactions present in the $\mathrm{Al} / \mathrm{SiC}$ wetting system under certain thermodynamics conditions:

$$
\begin{aligned}
& 4 \mathrm{Al}_{(\mathrm{l})}+\mathrm{Al}_{2} \mathrm{O}_{3(\mathrm{~s})} \rightarrow 3 \mathrm{Al}_{2} \mathrm{O}_{(\mathrm{g})} \uparrow \\
& 4 \mathrm{Al}+3 \mathrm{SiO}_{2} \rightarrow 2 \mathrm{Al}_{2} \mathrm{O}_{3}+3 \mathrm{Si}
\end{aligned}
$$

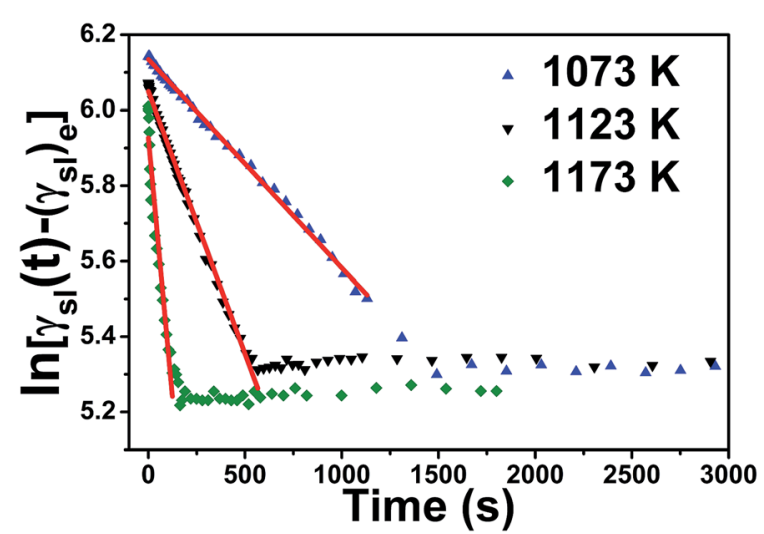

Fig. $4 \ln \left[\gamma_{s l}(t)-\left(\gamma_{s l}\right)_{e}\right]$ versus time for $\mathrm{Al}-7 \mathrm{wt} \% \mathrm{Si} / \mathrm{SiC}$ system at different temperatures. 


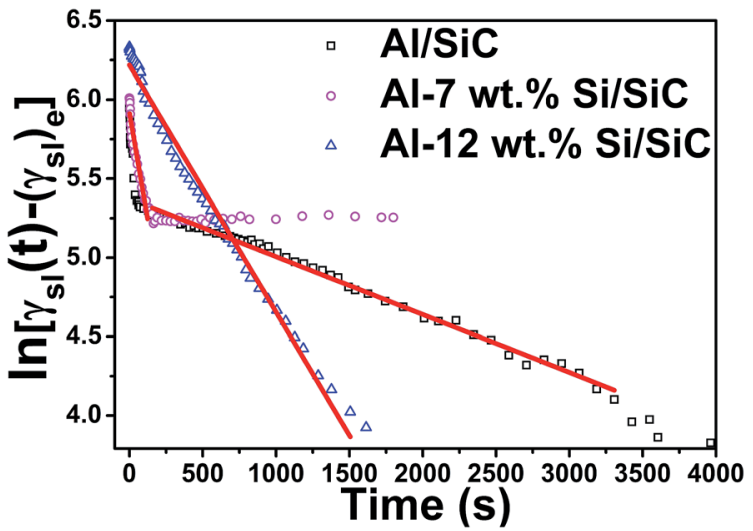

Fig. $5 \ln \left[\gamma_{\mathrm{sl}}(t)-\left(\gamma_{\mathrm{sl}}\right)_{\mathrm{e}}\right]$ versus time for $\mathrm{Al}-\mathrm{Si} / \mathrm{SiC}$ systems with different contents of Si at $1173 \mathrm{~K}$.

At the reaction-limited stage, the addition of $\mathrm{Si}$ indeed accelerates the reaction of $\mathrm{Al} / \mathrm{SiC}$ system. However, as $\sigma_{\mathrm{lv}}(\mathrm{Si})<$ $\sigma_{\mathrm{lv}}(\mathrm{Al})$, we suspect that $\mathrm{Si}$ tends to accumulate more easily on the surface of Al droplet after a much more addition of Si (e.g., $12 \mathrm{wt} \%)$, which will weaken the above reaction to some extent. As a result, the reaction rate of $\mathrm{Al}-12 \mathrm{wt} \% \mathrm{Si} / \mathrm{SiC}$ system will be slower than that of $\mathrm{Al}-7 \mathrm{wt} \% \mathrm{Si} / \mathrm{SiC}$ system.

\section{Conclusions}

In this work, we have proposed a new reactive wetting dynamics model to better explain the driving force and wetting mechanism on the basis of solid-liquid interfacial tension $\gamma_{\mathrm{sl}}$. This model indicates that the decrease of interfacial tension follows an exponential relation with spreading time:

$$
\gamma_{\mathrm{sl}}(t)=\left(\gamma_{\mathrm{sl}}\right)_{\mathrm{e}}+\left(\Delta \gamma_{\mathrm{sl}}\right)_{\max } \exp (-k C t)
$$

The $\gamma_{\mathrm{sl}}(t)$ curves at different temperatures converted from the $\theta(t)$ curves of $\mathrm{Al} / \mathrm{SiC}, \mathrm{Al}-7 \mathrm{wt} \% \mathrm{Si} / \mathrm{SiC}$ and $\mathrm{Al}-12 \mathrm{wt} \% \mathrm{Si} / \mathrm{SiC}$ systems have the synchronous decreasing tendencies with $\theta(t)$ curves as temperature increasing. In addition, the linear fitting results $\left(R^{2}>0.99\right)$ of the kinetics curves reveal that the driving force of reaction-limited wetting is indeed the variation of solidliquid interfacial tension $\Delta \gamma_{\mathrm{sl}}(t)$, confirming the rationality of the dynamics model we build. Moreover, the value of activation energy calculated in the reaction-limited spreading stage of $\mathrm{Al}$ / SiC system is $308 \mathrm{~kJ} \mathrm{~mol}^{-1}$, which is close to $330 \mathrm{~kJ} \mathrm{~mol}^{-1}$ in other reference.

As far as we know, the dynamics model, which appears to be well verified by experimental data, is first proposed to explain the spreading mechanism in terms of interfacial tension for reaction-limited wetting.

\section{Acknowledgements}

This work is supported by the program of the National Natural Science Foundation of China (50471007, 51102045). The authors are thankful to the Key Laboratory of Automobile
Materials in Jilin University for their kind help in high temperature experiment.

\section{References}

1 R. Bhola and S. Chandra, J. Mater. Sci., 1999, 34, 4883-4894.

2 V. H. López and A. R. Kennedy, J. Colloid Interface Sci., 2006, 298, 356-362.

3 N. Eustathopoulos, Acta Mater., 1998, 46, 2319-2327.

4 E. Saiz, C. W. Hwang, K. Suganuma and A. P. Tomsia, Acta Mater., 2003, 51, 3185-3197.

5 H. Kamusewitz, W. Possart and D. Paul, Colloids Surf., A, 1999, 156, 271-279.

6 D. E. Peebles, H. C. Peebles and J. A. Ohlhausen, Colloids Surf., A, 1998, 144, 89-114.

7 P. Shen, H. Fujii, T. Matsumoto and K. Nogi, Metall. Mater. Trans. A, 2004, 35, 583-588.

8 Y. Liang, S. J. Meschter and T. J. Singler, Acta Mater., 2004, 52, 2873-2888.

9 A. Mortensen, B. Drevet and N. Eustathopoulos, Scr. Mater., 1997, 36, 645-651.

10 A. Contreras, C. A. León, R. A. L. Drew and E. Bedolla, Scr. Mater., 2003, 48, 1625-1630.

11 K. Landry and N. Eustathopoulos, Acta Mater., 1996, 44, 3923-3932.

12 N. Eustathopoulos, J. P. Garandet and B. Drevet, Philos. Trans. $R$. Soc., A, 1998, 356, 871-884.

13 B. Drevet, K. Landry, P. Vikner and N. Eustathopoulos, Scr. Mater., 1996, 35, 1265-1270.

14 K. Landry, S. Kalogeropoulou, N. Eustathopoulos, Y. Naidich and V. Krasovsky, Scr. Mater., 1996, 34, 841-846.

15 L. Espié, B. Drevet and N. Eustathopoulos, Metall. Mater. Trans. A, 1994, 25, 599-605.

16 N. Eustathopoulos, Curr. Opin. Solid State Mater. Sci., 2005, 9, 152-160.

17 F. G. Yost, R. R. Rye and J. A. Mann, Acta Mater., 1997, 45, 5337-5345.

18 F. G. Yost and E. J. O'Toole, Acta Mater., 1998, 46, 51435151.

19 T. D. Blake and J. M. Haynes, J. Colloid Interface Sci., 1969, 30, 421-423.

20 P. G. D. Gennes, Rev. Mod. Phys., 1985, 57, 827-863.

21 O. Dezellus, F. Hodaj and N. Eustathopoulos, Acta Mater., 2002, 50, 4741-4753.

22 T. Young, Philos. Trans. R. Soc. London, 1805, 95, 65-87.

23 G. Kumar and K. N. Prabhu, Adv. Colloid Interface Sci., 2007, 133, 61-89.

24 N. Eustathopoulos and R. Voytovych, J. Mater. Sci., 2015, 51, 1-13.

25 M. Schmitt, K. Gross, J. Grub and F. Heib, J. Colloid Interface Sci., 2015, 447, 229-239.

26 L. Y. Zhang, P. Shen, Y. Qi and Q. C. Jiang, Appl. Surf. Sci., 2013, 276, 424-432.

27 P. Shen, Q. Lin and Q. Jiang, J. Mater. Res., 2009, 24, 24202427.

28 X. S. Cong, P. Shen, Y. Wang and Q. Jiang, Appl. Surf. Sci., 2014, 317, 140-146. 
29 M. Hoorfar and A. W. Neumann, Adv. Colloid Interface Sci., 2006, 121, 25-49.

30 D. Zhang, D. Y. Zhu, T. Zhang and Q. F. Wang, Trans. Nonferrous Met. Soc. China, 2015, 25, 2473-2480.

31 Y. S. Chiu and J. E. Zajic, Biotechnol. Bioeng., 1976, 18, 11671170.

32 D. Y. Zhu, X. M. Liao and P. Q. Dai, Chin. Sci. Bull., 2012, 57, 4517-4524.

33 G. W. Liu, M. L. Muolo, F. Valenza and A. Passerone, Ceram. Int., 2010, 36, 1177-1188.
34 J. Narciso, C. García-Cordovilla and E. Louis, Mater. Sci. Eng., $B, 1992,15,148-155$.

35 D. J. Lloyd, H. Lagace, A. Mcleod and P. L. Morris, Mater. Sci. Eng., A, 1989, 107, 73-80.

36 T. Iseki, T. Kameda and T. Maruyama, J. Mater. Sci., 1984, 19, 1692-1698.

37 H. Nakae, K. Yamamoto and K. Sato, Mater. Trans., 1991, 32, 531-538.

38 J. C. Lee, S. B. Park, H. K. Seok, C. S. Oh and H. I. Lee, Acta Mater., 1998, 46, 1771-1780.

39 T. Choh and T. Oki, Mater. Sci. Technol., 1987, 3, 378-385. 